\title{
Fotografias de uma anomalia. Alteridade e os limites da comunicação intercultural em situação colonial
}

\author{
Sílvio Marcus de Souza Correa Departamento de História, Centro de Filosofia e Ciências \\ Humanas, Universidade Federal de Santa Catarina, Brasil \\ https://orcid.org/0000-0002-0364-6590
}

No início de setembro de 1948, a Missão Antropológica de Moçambique (MAM) esteve em António Enes (atual Angoche). Nessa localidade, o chefe da MAM, Joaquim Rodrigues dos Santos Júnior, foi informado sobre a anomalia de um jovem. O interesse de Santos Júnior pelo caso do pequenino Atomane se inscreve numa teratologia colonial que deu azo para uma espetacularização científica dos corpos dos "indígenas". A anomalia de Atomane é apenas uma de várias outras registadas durante as campanhas das missões antropológicas a Guiné, Angola, São Tomé e Príncipe, Moçambique e Timor, realizadas entre 1936 e 1959. As fotografias do pequeno Atomane e outros materiais do espólio da MAM formam o corpus documental para a análise dos limites da comunicação intercultural em contexto colonial. A partir de novos aportes em cultura visual, faz-se uma leitura crítica de fotografias do arquivo colonial da MAM.

Palavras-chave: fotografia, antropologia, colonialismo, Moçambique

\section{Photographs of an anomaly. Alterity and the limits of intercultural communication in a colonial situation}

\begin{abstract}
In early September 1948, the Mozambique Anthropological Mission (MAM) was a few days in António Enes (now Angoche). Joaquim Rodrigues dos Santos Júnior, head of MAM, was informed of the anomaly of a young man. Santos Júnior's interest in the case of the little Atomane was part of a colonial teratology that gave rise to a scientific spectacularization of the colonized bodies. Atomane's anomaly is just one of several others recorded during the overseas anthropological missions to Guinea, Angola, São Tomé and Príncipe, Mozambique and Timor, between 1936 and 1959. The photographs of Atomane and the MAM's collection form the documentary corpus for the analysis of the limits of intercultural communication in colonial context. Based on new contributions in visual culture, the study provides a critical reading of the photographs from MAM's colonial archive.
\end{abstract}

Keywords: photography, anthropology, colonialism, Mozambique

Submetido: 01/05/2021 | Revisto: 02/06/2021 | Aceite: 02/06/2021 | Publicado: 29/06/2021

\section{As fotografias da Missão Antropológica de Moçambique}

A Missão Antropológica de Moçambique (MAM) foi criada pelo Decreto-Lei n. $\stackrel{0}{ } 34.478$ de 3 de abril de 1945. Esta foi precedida pela Missão Etnográfica e Antropológica de Moçambique, por sua vez, criada pelo Decreto-Lei n.o 26.842 de 28 de julho de 1936. De 1936 a 1956, foram realizadas seis 
campanhas em Moçambique sob a chefia do médico Joaquim Rodrigues dos Santos Júnior. Milhares de fotografias foram feitas durante as campanhas científicas da MAM. O seu espólio fotográfico encontra-se, atualmente, no Arquivo Histórico Ultramarino em Lisboa. Para o presente artigo, temse por fonte e objeto de estudo um conjunto de fotografias da $5 .^{a}$ campanha da MAM, realizada em 1948. Para essa expedição, o chefe da MAM não contou com a colaboração de um fotógrafo profissional por razões orçamentárias. Santos Júnior (1948) reclamou da falta de um fotógrafo em seu relatório: "tiramos bastantes fotografias. Faz falta à Missão um fotógrafo, que quis agregar, e que tomaria não só o encargo de tirar fotografias durante os trabalhos de campo, mas também o da revelação e das provas e ampliações" (p. 40).

Durante a $5 .^{\text {a }}$ campanha da MAM, as fotografias foram feitas pelos membros da equipa. Um pequeno número dessas fotografias foi reproduzido nos relatórios e nos artigos publicados por certos integrantes da MAM. Porém, a maioria das fotografias permaneceu simplesmente arquivada. Nos últimos anos, alguns trabalhos acadêmicos têm usado as fotografias da MAM como fontes e/ou objetos de estudos. As fotografias e negativos da MAM contêm muitas informações visuais. Para lograr uma compreensão satisfatória dessas fontes visuais, cabe contextualizá-las, especialmente aquelas da campanha de 1948, quando o jovem Atomane caiu na malha fina da Antropologia portuguesa e sua teratologia colonial.

Além da sua utilidade para a propaganda colonial, a Antropologia era uma ciência instrumental da então denominada "política indígena" (R. Pereira, 2005). Segundo o chefe da MAM, "a antropologia é um dos melhores, senão o melhor instrumento ao serviço da política indígena" (Santos Júnior, 1948, p. 4). Acrescentou que "a antropologia fornece, como nenhuma outra Ciência, elementos basilares para a orientação da política indígena" (Santos Júnior, 1948, p. 4).

As campanhas que Santos Júnior chefiou tinham por objetivo geral um estudo antropológico que permitisse fazer uma cartografia étnica de Moçambique. Conforme o próprio Decreto-Lei n. 26.842 de 28 de julho de 1936, o objetivo da MAM era proceder ao "conhecimento dos grupos étnicos de cada um dos nossos domínios ultramarinos, ou seja, a elaboração das respectivas cartas etnológicas". Para isso, a Antropologia, "estabelecendo as afinidades somáticas, procura descobrir parentescos ou definir, com precisão, a natureza étnica das diferentes tribos" (Santos Júnior, 1948, pp. 4-5).

Com a 5. ${ }^{\mathrm{a}}$ campanha da MAM, Santos Júnior (1948, p. 16) visava esclarecer: (1) origem e relações das populações; (2) condições de vitalidade e de robustez dos vários grupos étnicos; (3) aptidões e tendências predominantes dos mesmos grupos. Essa campanha tinha ainda por prioridade o estudo do deslocamento das populações e de suas capacidades de adaptação à economia colonial. Santos Júnior (1948) atentou para o que chamou de problema demográfico do deslocamento: "a solução que parece impor-se é a fixação da gente e sobretudo dos excedentes populacionais, em regiões cujo solo possa ser explorado em regime de irrigação e permita aldeamento fixo" (p. 39). Segundo o próprio Santos Júnior (1948):

tal estudo deverá ser feito tendo em atenção as características psicológicas das ditas populações no referente ao seu modo de ser nómada ou não, aos hábitos de trabalho, aptidões, semelhança com os povos para junto dos quais vão viver, etc. Deverá indicar pois quais as populações a deslocar e os locais, onde isso convenha fazer-se, dando preferência àqueles em que estejam localizadas grandes empresas;

Estudará a possibilidade do aldeamento das populações de modo a dar incremento às grandes povoações. Tal concentração conviria ser orientada no sentido de se tirar maior rendimento das culturas por elas feitas, de modo a diminuir o seu preço de custo e permitir uma maior fiscalização sobre os processos de trabalho por elas empregado. (p. 22)

Além do deslocamento populacional e da fixação dos "indígenas" em novos aldeamentos para uma 
economia colonial com base na exploração da agricultura intensiva, o chefe da MAM também anteviu o deslocamento dos "indígenas" para a indústria.

Neste particular da mão de obra para as indústrias parece ser de considerar a conveniência de fazer o recrutamento dos primeiros artífices nas tribos ou nos agregados populacionais que se apresentem sob o ponto de vista psicotécnico como melhores condições de adaptação aos serviços a que se destinarem.

Os preceitos da orientação profissional manejados convenientemente em tetes adequados darão a indicação daqueles que poderão prestar melhor serviço.

Não basta, porém, o conhecimento das faculdades de ordem psíquica, é necessário que às mesmas se juntem qualidades de ordem somática, de resistência física.

O estudo antropológico geral fixando as características somáticas e o estudo médico complementar permitirão selecionar convenientemente os lotes de artífices a empregar nos primeiros ensaios de adaptação à mão de obra industrial.

Desta forma a Antropologia em estreita colaboração com a técnica concorrerá para a resolução de um importante problema de ordem demográfica da maior importância social e política. (Santos Júnior, 1948, p. 40)

Disciplinas como Arqueologia, Antropologia e Etnologia concorriam para uma "ciência colonial" marcada pela teleologia salazarista na qual a assimilação dos "indígenas" era uma das finalidades da colonização. Posto que o futuro já estaria pré-estabelecido pelo Estado Novo, cabia à MAM o estudo do passado e do presente dos "indígenas". A referida teleologia tem interface com a orientação do trabalho de campo das missões antropológicas. Desse modo, a MAM de 1948 seguiu a mesma lógica política e científica das demais missões antropológicas que, ao fim e ao cabo, corroboravam a racialização e a tribalização dos então chamados "indígenas".

Todavia, o aporte científico dos inquéritos tribais e que orientou a coleta dos dados pela MAM comprometeu o alcance dos resultados. As categorias de raça e tribo levaram Santos Júnior a pressupor uma "pureza étnica" no horizonte de suas investigações. Em termos metodológicos, a MAM recorreu a critérios seletivos para obter exemplares "puros" de um determinado grupo étnico. O racialismo e o tribalismo impostos pelos esquemas teóricos que orientavam às campanhas de investigação da MAM predominaram em detrimento das complexas relações de parentesco e das identidades étnico-linguísticas em Moçambique. Na ausência de qualquer referência a uma antropologia cultural, os referenciais teórico-metodológicos da MAM não davam contam da complexa realidade, sobretudo daqueles grupos mestiços ou destribalizados. Desse modo, a cartografia étnica elaborada pela equipa da MAM foi mais uma ficção de antropologia colonial.

Mas há quem considere que a MAM produziu e recolheu um conjunto de materiais e documentos que permite, ainda hoje, um outro olhar sobre a terra e as gentes de Moçambique (Rodrigues, 1990). Da 5. ${ }^{a}$ campanha, acredita-se que

a globalidade da documentação produzida durante esta campanha possibilita uma visão mais sistemática dos trabalhos efetuados e permite o acesso a um conjunto de dados que pode hoje vir a ser utilizado num outro contexto que não o exclusivamente colonial. (Roque \& Ferrão, 2012, p. 227)

No que tange à $5 .^{\mathrm{a}}$ campanha da MAM, esta apresenta algumas particularidades. Entre outras, destaco um relatório datilografado que nunca foi publicado. Por não ter passado pelo crivo da censura, o texto contém alguns aspetos que não se encontram em outros relatórios da MAM sobre 
as condições de investigação durante o trabalho de campo (R. Pereira, 2005, p. 218). Outras questões foram as novas prioridades que a Junta das Missões Geográficas e de Investigações Coloniais (JMGIC) estabeleceu para a campanha da MAM de 1948 e que deixa evidente a instrumentalização da investigação científica em prol da política "indígena" e da economia colonial. Apesar do plano ambicioso de engenharia social com projetos de deslocamento populacional e de novos aldeamentos com base em estudos científicos, a JMGIC não atendeu o pedido de triplicar o número dos colaboradores da equipa da MAM. Através da Portaria n.o 12.215, de 26 de dezembro de 1947, o Ministro das Colónias, Capitão Teófilo Duarte, disponibilizou apenas seis colaboradores. Um deles foi o jovem Joaquim Norberto dos Santos Júnior, estudante de Antropologia Física no Porto e filho do chefe da MAM. Ele foi contratado com o vencimento de 2.250 escudos mensais, conforme o que estabelecia a portaria acima referida para o cargo de primeiro assistente (Santos Júnior, 1948, p. 25). O ajudante Joaquim Norberto dos Santos Júnior já havia participado de outras missões. Em 1948, ele foi o responsável pela realização de grande quantidade de impressões dermopapilares e de fotografias científicas da MAM.

\section{Um encontro anunciado}

A chegada da equipa da MAM numa circunscrição era informada com antecedência "de modo a que as autoridades administrativas possam [se] concentrar nos locais convenientes duas ou três centenas de indígenas adultos de ambos os sexos e, se possível, de idades entre os 25 e os 40 anos" (Santos Júnior, 1948, p. 22). Algumas vezes, o número de pessoas era inferior ao esperado ou as pessoas recrutadas não correspondiam à faixa etária para as amostras. Houve lugares onde a concentração de pessoas foi além da expectativa.

Em certos lugares, o chefe da MAM se deparou com uma realidade inesperada, na qual a "fusão de quase todas as tribos do Niassa" resultou num "imbróglio enorme" (Santos Júnior, 1948, pp. 63-64). Para ele,

Quissanga não é, indubitavelmente, zona de eleição para os estudos antropológicos que a Missão vem realizando, e em que se tem procurado, além de outros objetivos, apurar os caracteres étnicos de ordem geral que possam, porventura, definir ou caracterizar as atuais tribos e subtribos de Moçambique. (Santos Júnior, 1948, pp. 63-64)

A elaboração do mapa étnico de Moçambique resultou em dezenas de grupos em que povo e território formaram unidades fixas por vínculos espaciais e temporais. Porém, o que fazer com os mestiços e com os destribalizados? Esses quase somem do mapa, pois a MAM evitou incluir os mestiços em seus inquéritos tribais. Por outro lado, a MAM tinha um interesse pelos corpos anômalos. O caso do jovem Atomane parece ser emblemático de uma teratologia colonial.

Atomane foi levado pelo seu pai para o encontro com Santos Júnior na localidade de António Enes em setembro de 19481. Assim como outros administradores de circunscrição, Henrique do Carmo Júnior foi incumbido de providenciar os voluntários para a coleta de dados realizados pela MAM. Provavelmente, Henrique do Carmo Júnior convocou o pai do jovem Atomane para trazer o seu filho em determinado dia. Com base em instruções recebidas previamente, o administrador da circunscrição deve ter julgado o caso de Atomane digno dos estudos da MAM.

A fotografia de Atomane com o seu pai (Figura 1) deve ter sido feita após as medições feitas pela equipa da MAM. Percebe-se um alfinete de fantasia no bolso da camisa do rapaz, um presente que lhe foi dado por um dos membros da MAM. A expressão facial do pai de Atomane interpela o espectador. Teria trazido o seu filho com alguma esperança de cura? Qual seria a sua expectativa? Teria vindo apenas para atender uma convocatória? Ou ele atribuía algum poder ao saber ou à magia de muzungo? Para usar um termo de Alfred Schütz (1998), qual estoque de conhecimento (stock ofknowledge) mobilizou o pai de Atomane para interagir com a equipa da MAM? Não duvido 
que ele tivesse alguma esperança que os muzungos pudessem fazer algo para curar o seu filho. Mas não havia ciência ou magia para curar a microcefalia, o que não impediu Atomane de ser medido, despido, fotografado e examinado.

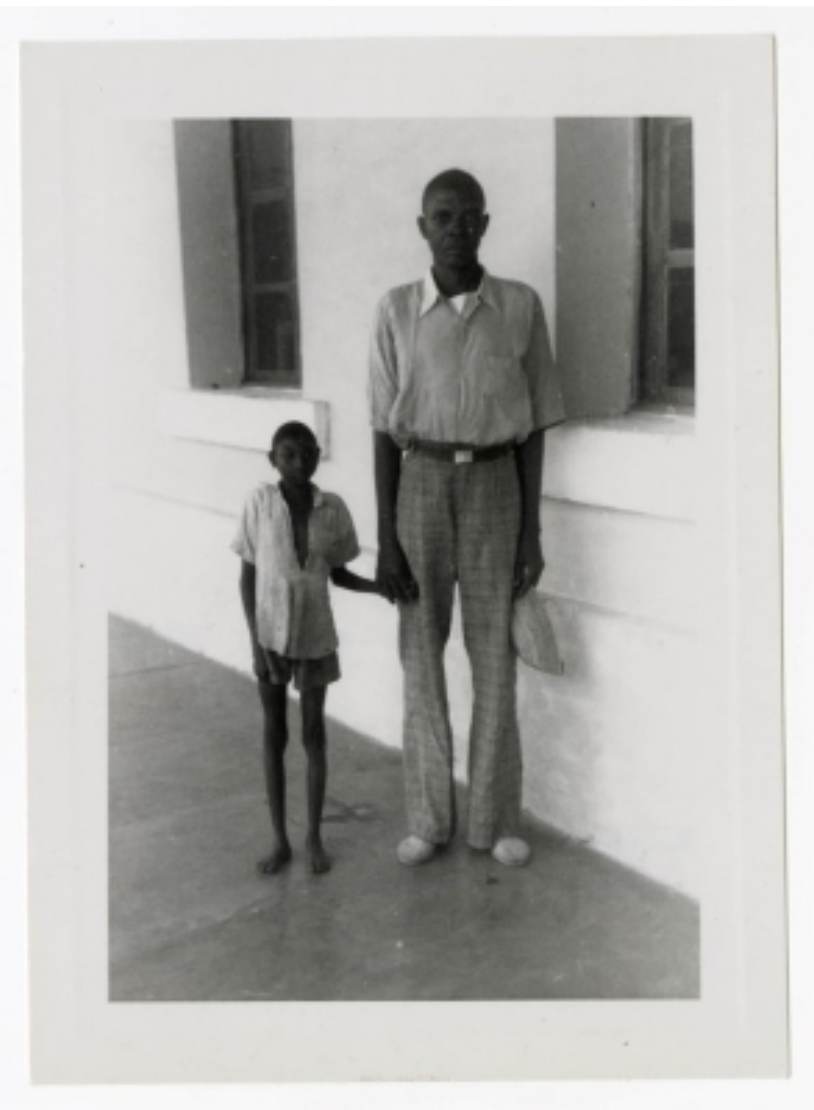

Figura 1. Atomane com o seu pai IICT-Photography Collection, Inv. ULISBOA-IICT-MAM (1948)

\section{"Medimo-lo todo"}

Em 1948, Atomane tinha 22 anos de idade, conforme informação do administrador da circunscrição de António Enes, de "onde ele é natural e onde vive este pretinho que deve ser um dos mais pequeninos de Moçambique". Tinha o "corpo franzino como de menino" (Santos Júnior, 1949, p. 1). Foi submetido a medições antropométricas. Como escreveu Santos Júnior (1949): "medimo-lo todo" (p. 1).

Segundo as anotações de Santos Júnior, Atomane tinha 113 centímetros de altura e pesava 13 quilos e 500 gramas. Para o chefe da MAM, tratava-se de um caso de nanismo com infantilismo cuja causa seria uma insuficiência endócrina (da glândula Timo). Sobre o seu aspecto morfológico, destacou Santos Júnior (1949): a "cabeça esferoidal", "acentuada pobreza muscular" e "corpo escorrido de carnes" (p. 3). Sobre os órgãos sexuais, o chefe da MAM informou sobre o tamanho do pênis, a morfologia dos testículos e do canal inguinal. O infantilismo observado por Santos Júnior (1949) não estava apenas associado à genitália de Atomane, mas também à sua voz, pois a "vozinha era fraca, fina, e de tonalidade infantil" (p. 3).

Para Santos Júnior (1949), o pequenino de António Enes apresentava acentuado grau de microcefalia o que "não seria de estranhar se este pretinho não falasse" (p. 3). O falar de Atomane não pareceu fácil ao observador que atribuiu a dificuldade à sua dentição "bastante anômala", com 21 dentes, dos quais "13 no maxilar superior e 8 no inferior" e porque o jovem não era "propriamente um palrador" (Santos Júnior, 1949, p. 3). Pode-se ainda conjeturar que a interação 
entre o muzungo e o "indígena" na língua portuguesa foi um fator inibidor para o último.

A lista com todas as medidas antropométricas de Atomane serviu para a comunicação de Santos Júnior durante o "VI Congresso de Anatomia Luso-Hispano-Americano" e a "XIX Reunião da Sociedade Anatómica Portuguesa", realizada em Lisboa, entre 15 e 18 de maio de 1949. Da lista de medidas de Atomane, algumas delas remetem à antropologia criminal do final do século XIX, como as dos diâmetros frontais da cabeça, frontal máximo e vértico-transversal. Nos apontamentos de Santos Júnior, não há informação sobre testes psicotécnicos realizados com Atomane. Mas o chefe da MAM comentou que, pela aparente curiosidade que prestava às medições "que lhe íamos fazendo, deixou-nos a impressão de certo grau de inteligente confiança" (Santos Júnior, 1949, p. 1). Atomane foi descrito como "sorridente", com "olhar vivo e arguto": "sempre que nos olhava sorria confiante e prazenteiro" (Santos Júnior, 1949, p. 1). Ainda sobre a alteridade do "microcéfalo de António Enes", Santos Júnior (1949) comentou um fato que atestava a sua empatia, "o seu grau de sensibilidade" (p. 1):

os companheiros da Missão e eu mesmo demos ao Atomane alguns alfinetes de fantasia que ele trazia pregados na blusinha. Um preto das escolas rudimentares da Missão Católica de Malatane furtou ao Atomane um dos alfinetes, o mais vistoso e certamente o de mais agrado do nosso anãozinho.

Não sei como o fato chegou ao conhecimento do padre Celso que castigou o furtador com algumas palmadas. O castigado chorou. Pois bem, ao pequenino Atomane, que assistiu ao castigo, lhe rolaram as lágrimas pela face. (p. 2)

Para o chefe da MAM, a empatia manifestada por Atomane era uma prova de que a microcefalia não afetara a sua sensibilidade e a sua alteridade. O retrato de Atomane (Figura 2) e outras fotografias dele, inclusive nu, demonstram que as instruções do fotógrafo foram atendidas. Nesse sentido, a comunicação entre o sujeito fotografado e o fotógrafo foi decisiva para o resultado final. Contudo, a comunicação intercultural entre o antropólogo e o "indígena" parece ter sido comprometida pela anomalia. Provavelmente, o chefe da MAM e o seu filho Norberto procuraram obter informações em conversa com o pequeno Atomane e com o seu pai. Mas o contexto colonial no qual transcorreu a interação social entre os membros da MAM e os "indígenas" em situação colonial limitava a pretensa comunicação intercultural. Críticas a esses limites do trabalho de campo já eram esboçadas em meados do século XX, como as de Michel Leiris (1950) em seu ensaio "O etnógrafo perante o colonialismo". Na altura, a Antropologia portuguesa seguia uma "linha dura" que atrelava o saber científico ao projeto colonial do regime salazarista. Nesse sentido, as fotografias de Atomane fazem parte de uma teratologia colonial que tinha interface com a espetacularização da anomalią2. 


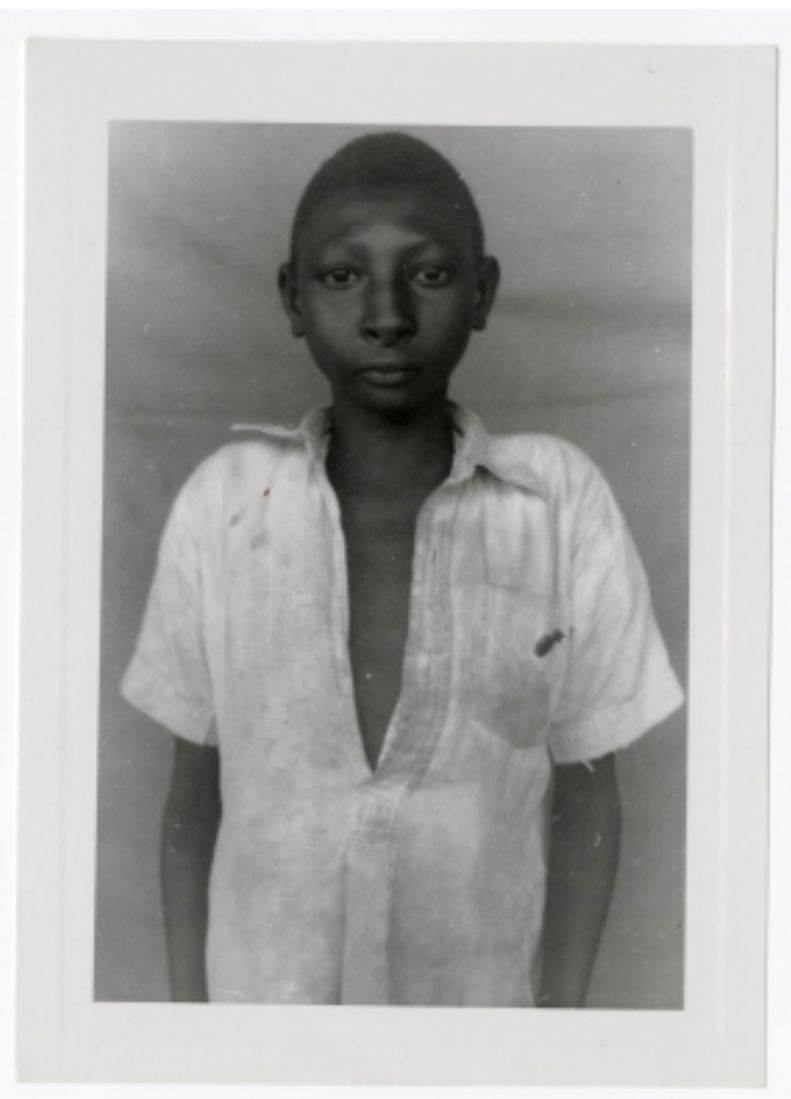

Figura 2. Atomane Fonte: IICT-Photography Collection, Inv. ULISBOA-IICT-MAM (1948)

\section{Microcefalia e teratologia colonial}

A microcefalia foi objeto de estudo da medicina portuguesa desde Miguel Bombarda (1894). Mendes Corrêa fez o seu doutorado sob a direção de tese de Miguel Bombarda. Por seu turno, Santos Júnior era discípulo de Mendes Corrêa. Provavelmente, ele conhecia esses primeiros estudos sobre a microcefalia em Portugal. Escusado é lembrar que Miguel Bombarda discordou da tese de Carl Vogt, na qual a microcefalia era considerada uma regressão evolutiva. Para o preclaro médico português, o microcéfalo não era um "homem-macaco" como pretendia Carl Vogt. Apesar da crítica de Bombarda a Vogt em 1894, o microcéfalo continuou a ser visto por muitos como um "homem-macaco"; inclusive, como "bicho de feira". Em 1911, um empresário de um animatógrafo de Lisboa expôs ao público o pequeno António, cujas "atitudes simianas" tencionava ainda aperfeiçoar para o espetáculo (Cascais, 2016, pp. 104-105). O pequeno Atomane não se tornou "bicho de feira". Ele não apresentava os estigmas do "homem-macaco". Assim como a situação colonial, a diligência, a presteza e a falta de agressividade de Atomane impedem certas comparações, em termos comportamentais, com os casos de microcefalia que serviram aos estudos de Miguel Bombarda (1894), João Neves (1898), Júlio de Matos (1911) e Ernesto Roma (1913).

O interesse de Santos Júnior pelo caso do pequenino Atomane estava em consonância com um dos objetivos da campanha da MAM de 1948, ou seja, avaliar a robustez e a vitalidade das populações estudadas. Desde as primeiras campanhas da MAM, as anomalias foram objetos de estudos (Santos Júnior, 1939). A teratologia colonial acompanhou os estudos sobre a robustez e a vitalidade dos grupos étnicos. Com a régua da "pureza racial" procurou-se medir os "indígenas" para compará-los e identificar aqueles superiores (mais "puros") e aqueles inferiores (menos "puros").

Como as missões antropológicas tinham interesse por grupos "mais puros", aqueles "menos puros" foram considerados, às vezes, como residuais numa linha evolutiva. Porém, a miscigenação 
colocava em cheque alguns postulados das missões antropológicas. Nos relatórios e nos artigos de António de Almeida ou de Santos Júnior, nota-se que a miscigenação era uma variável independente, um fator que comprometia alguns resultados científicos.

Em meados do século XX, formulava-se ainda a hipótese de que algumas anomalias poderiam estar associadas à degeneração racial. A relação entre degenerescência e hereditariedade era a base da teoria do francês Bénédict Augustin Morel (1857) já formulada em seu Traité des dégénérescences. A teoria de Morel teve impacto direto sobre a Medicina em Portugal, como no trabalho de Basílio Freire (1886), e também sobre a Antropologia portuguesa do final do século XIX, notadamente a Antropologia Criminal e cujo grande paladino foi Francisco Ferraz de Macedo (1899). Formado em Ciências Naturais e Farmacêuticas pela Faculdade do Rio de Janeiro, e em Medicina e Cirurgia pela mesma universidade, Ferraz de Macedo era sócio efetivo da Sociedade de Antropologia de Paris. Como delegado oficial do governo português, ele participou no "Congresso de Antropologia Criminal", realizado em Genebra entre os dias 24 e 29 de agosto de 1896 (Macedo, 1900).

Francisco Ferraz de Macedo foi um dos primeiros a tratar da degeneração e miscigenação em contexto colonial. Foi ele também o autor de um mapeamento "físico-intelecto-moral" (Macedo, 1877). O seu mapa sintético apresenta um quadro comparativo de 16 nacionalidades com base em 21 quesitos. Justificou não agrupar os habitantes de nações por raças, pois "a civilização de uns influenciando sobre outros tem-lhes modificado profundamente o ritmo ético característico primitivo" (Macedo, 1877). Francisco Ferraz de Macedo empregou a categoria gênero (masculino e feminino) para a elaboração do seu mapa sintético de "ética e etnologia parcial".

A influência das teorias de B. A. Morel, Cesare Lombroso e Paul Broca continuou na Antropologia portuguesa das primeiras décadas do século XX, sob a égide de Mendes Corrêa. Assim como no pensamento de Ferraz de Macedo, algumas teses da Antropologia Criminal não foram defendidas pela "escola do Porto". No entanto, as missões antropológicas atualizaram algumas questões já levantadas desde o início da Antropologia em Portugal. Para compor suas amostras, a MAM teve dificuldades em encontrar os tipos "normais", aqueles que corresponderiam ao "talão normal de uma raça", para usar uma expressão de Ferraz de Macedo (1900) quando tratou do assunto em seus Bosquejos de Antropologia Criminal. Ora, ao procurar um tipo normal de homem, a Antropologia Física confrontou-se com os desvios. O normal remetia ao anormal não apenas em termos fisiológicos, mas também em relação aos hábitos sociais e morais 3 .

Santos Júnior $(1944,1945)$ não se incomodou pelo facto de algumas anomalias não poderem ser associadas a uma raça ou a uma tribo, embora ambas as categorias fossem de fulcral importância no esquema antropológico de mapeamento dos grupos humanos. Na verdade, nenhuma anomalia foi estudada com profundidade pelo chefe da MAM. Nos relatórios e documentos produzidos por Santos Júnior, as anomalias - como o nanismo de Atomane - não passaram de meros objetos de sua curiosidade e cujos comentários superficiais apresentavam não mais que um verniz científico já com craquelés a uma Antropologia Colonial em crise a partir dos meados do século XX.

Alguns temas correlacionados com as anomalias foram abordados também de forma superficial por Santos Júnior, inclusive em conferências para um público leigo. Em Moçambique, por exemplo, Santos Júnior fez uma série de palestras durante a quinta campanha da MAM em cidades como Beira, Nampula e Quelimane. Nessa última, o título de sua palestra foi Como se deve estudar um preto do ponto de vista antropológico. Outras comunicações foram feitas na metrópole para um público mais seleto. O caso de nanismo com infantilismo de Atomane foi tema de uma comunicação de Santos Júnior durante o "VI Congresso de Anatomia Luso-Hispano-Americano" e a "XIX Reunião da Sociedade Anatómica Portuguesa", realizada em Lisboa, entre 15 e 18 de maio de 1949. Embora podesse recorrer a fotografias de Atomane para ilustrar a sua comunicação, bem como aos desenhos e às impressões dermopapilares dos pés e das mãos do "microcéfalo de António Enes", Santos Júnior pouco acrescentou ao saber médico sobre a microcefalia. A sua comunicação foi um exemplo da espetacularização científica e colonial de uma anomalia identificada numa circunscrição de uma província ultramarina. 
Como a microcefalia é uma patologia incurável, a fotografia se limita a restituir a prova da impotência terapêutica (Cascais, 2016, p. 105). O conjunto de fotografias de Atomane evidencia o limite da ciência. Se as imagens de Atomane revelam ao espectador um enigma que a ciência não podia decifrar, elas indicam outrossim que os atos de fotografar, perscrutar, medir e observar passam a ter outras finalidades, uma vez que a anormalidade do sujeito fotografado parece confirmar a normalidade de quem fotografa, perscruta, mede e observa.

\section{Fotografias e as províncias de significado em contexto colonial}

No final do século XIX, o processo fotográfico como uma cópia fidedigna da realidade seduzia muitos no campo das Artes e das Ciências $\underline{4}$. O mito da objetividade fotográfica teve na fotografia científica o seu último refúgio. Em Portugal, a Antropologia da chamada "escola do Porto" fez da fotografia um importante instrumento do seu método científico (P. Matos, 2014). Assim como nas campanhas anteriores, a 5. ${ }^{\mathrm{a}}$ campanha da MAM recorreu à fotografia como um procedimento de recolha de dados para as suas investigações científicas. Juntamente com milhares de fotografias das campanhas da MAM e de outras missões em Guiné ou Angola, pode-se compor um corpus iconográfico de uma teratologia colonial. Corpos com anomalias foram alvos da curiosidade científica e as imagens fotográficas não raro acusam um olhar indecente e obsceno. Em geral, essas campanhas da MAM não tinham muitos cuidados com a presença do antropólogo como elemento perturbador numa comunidade. Entre outras ações da equipa da MAM, o ato fotográfico constrangia, não raro humilhava, quem era exposto à lente objetiva.

Não se deve olvidar que a exibição de milhares de indivíduos diante da máquina fotográfica fez parte da recolha de informações da MAM para elaboração de índices de robustez e vitalidade e, por conseguinte, para identificar e situar os grupos numa hierarquia racial (R. Pereira, 2005). Os relatórios da MAM serviam não apenas para a polícia "indígena", mas também para o desenvolvimento económico das colónias. Segundo Santos Júnior (1948): “a utilização racional e equitativa do fator humano da colónia de Moçambique exige o prévio conhecimento científico das características somato-físico-psicológicas dos seus elementos étnicos" (p. 15). O chefe da MAM não questionou o utilitarismo do conhecimento científico e dos seus índices artificiais de robustez e vitalidade dos povos para transformá-los em mera força de trabalho. A Antropologia de Santos Júnior pode ser vista como uma disciplina auxiliar da engenharia social responsável pelo incremento de um projeto colonial nos trópicos. Na verdade, o discípulo de Mendes Corrêa não estava longe do pensamento de um dos primeiros antropólogos portugueses, Adolfo Coelho (1893), que era assaz otimista em relação à seleção artificial aplicada para a colonização: "um processo análogo poderia elevar o negro d'África a um nível superior, fazer dele não um equivalente do europeu, mas um homem utilíssimo para a expansão e desenvolvimento da nossa civilização" ( $\mathrm{p}$. 39).

Ao contrário do que Adolfo Coelho vaticinara, a Antropologia Colonial promoveu a reificação do outro. O espólio fotográfico das missões antropológicas entre 1936 e 1959 contém vários exemplos. Como, então, encontrar nessas fotografias a subjetividade perdida das pessoas fotografadas? Como ver o retrato de Atomane para além de um caso de nanismo com infantilismo? Como identificar uma performance do sujeito fotografado e que tenha deixado alguma marca no resultado final? Para lograr uma aproximação cognitiva do "mundo" de Atomane a partir das fotografias, a noção de "província de significado" pode ser útil.

Alfred Schütz (1998) desenvolveu a sua abordagem fenomenológica das sociedades complexas, inspirado na teoria de William James das diferentes realidades nas quais se vive simultaneamente. A partir do seu interesse pela maneira como os indivíduos ajustam suas condutas com base em suas expectativas, em sua vida cotidiana e ao seu estoque de conhecimento, Alfred Schütz propõe uma hermenêutica da intersubjetividade para uma sociologia compreensiva. Mas como pensar o interacionismo em contexto colonial? Como indivíduos de diferentes grupos em situação colonial 
podem desenvolver uma comunicação intercultural?

Para Alfred Schütz (1998), a orientação da relação entre "u" e os "meus próximos" (we-relationship) difere daquela entre "nós" e os "outros" (they-relationship). Em contexto colonial, como compreender a interação de subjetividades dotadas de diferentes experiências do mundo? Segundo Schütz (1998),

na relação face to face, eu provo diretamente a presença do outro pela sua corporalidade viva. Espacialmente, isso significa que ele ocupa uma posição, u m lugar em relação ao meu lugar (...) Eu ocupo através do meu corpo, um ponto zero, a partir do qual se posici onam o mundo e meus semelhantes. (p. 98)

Em seu ensaio sobre Don Quixote e o problema da realidade, Schütz (1998) demonstrou que, dentro da província de significado que constitui o universo do "cavaleiro da triste figura", as premissas mantém a sua coerência e harmonia internas (p. 129).

Durante as campanhas da MAM, resta saber como as medições dos corpos e as fotografias eram percebidas pelos "indígenas". Feitiçarias de muzungo? Talvez. Deve-se ter em conta que as ações interativas entre a equipa da MAM e os "indígenas" foram vazadas por diferentes códigos culturais e orientadas pelas expectativas dos membros do in-groupe do out-group. Havia ainda o fator tempo, pois a equipa da MAM interagia com os "indígenas" em estadias de curta duração e, por conseguinte, sem muito controle dos efeitos perturbadores da sua presença nas comunidades. Cabe lembrar que desde os anos 1920, o método etnográfico de Bronislaw Malinkowski (1922) enfatizava a importância de uma presença normalizada e não perturbadora na comunidade estudada. A permanência prolongada permitia uma imersão (quase) total e um conhecimento advindo em grande parte da participação na vida cotidiana do grupo estudado. Nesse sentido, as informações visuais contidas numa imagem fotográfica podem variar de acordo com o tempo de imersão do trabalho de campo $\underline{5}$.

Durante a $5 .^{\text {a }}$ campanha da MAM, as fotografias foram feitas por quem não tinha uma presença normalizada nas comunidades onde houve a recolha de dados. Para alguns propósitos científicos da MAM, a presença perturbadora do antropólogo/fotógrafo parecia irrelevante. Malgrado o modo como eram feitas algumas fotografias em contexto colonial, certas "manipulações" e escolhas do fotógrafo ou sinais de contrariedade por parte do sujeito fotografado indicam convenções que acabam por determinar o resultado final. O artificialismo de algumas fotografias de corpos em situação colonial não necessariamente invalida a imagem fotográfica, pois as informações visuais têm relação com certas convenções que, por sua vez, regem a interação social entre fotógrafo e sujeito fotografado. Essas convenções podem ser percebidas na parte visível de uma fotografia, mas elas também remetem ao que ficou de fora da imagem.

As fotografias de Atomane podem ser vistas a partir de uma reversão de perspectiva, o que permite observá-las não somente com a atenção voltada para ele, mas também para quem está fora do registo visual, ou seja, o fotógrafo. Em contexto colonial, a imagem da alteridade foi racializada $\underline{6}$. No caso de Atomane, o modo como ele foi fotografado revela os conhecimentos prévios e as crenças do fotógrafo sobre a alteridade "indígena" e sobre a microcefalia. Ao invés de abordar o sujeito fotografado, aproximar o foco da análise sobre quem fotografa, ou seja, observar quem observa e não apenas quem foi observado, faz com que a fotografia seja mais um produto da estigmatização do que um registo visual do estigma.

A fotografia do filho do chefe da MAM com Atomane (Figura 3) parece emblemática dos limites da comunicação intercultural. Ambos devem ter a mesma idade. A fotografia pode ser analisada na lógica binária dos termos colonizador e colonizado, branco e negro ou simplesmente normal e anormal. Ela tem similaridade com outras fotografias de exploradores europeus com os chamados pigmeus da África equatorial. Prefiro seguir outras pistas. O ajudante da MAM está sentado 
enquanto Atomane posa em posição ereta, levemente inclinada e apoiada sobre a perna do jovem português. Mas o que representa para os códigos de Norberto e Atomane aquelas posições? Seus corpos se tocam. Ambos olham para a câmera. Logra-se uma imagem de um encontro amistoso entre o jovem estudante de antropologia e o "indígena". Demarcadas estão a alteridade e a (a)normalidade.

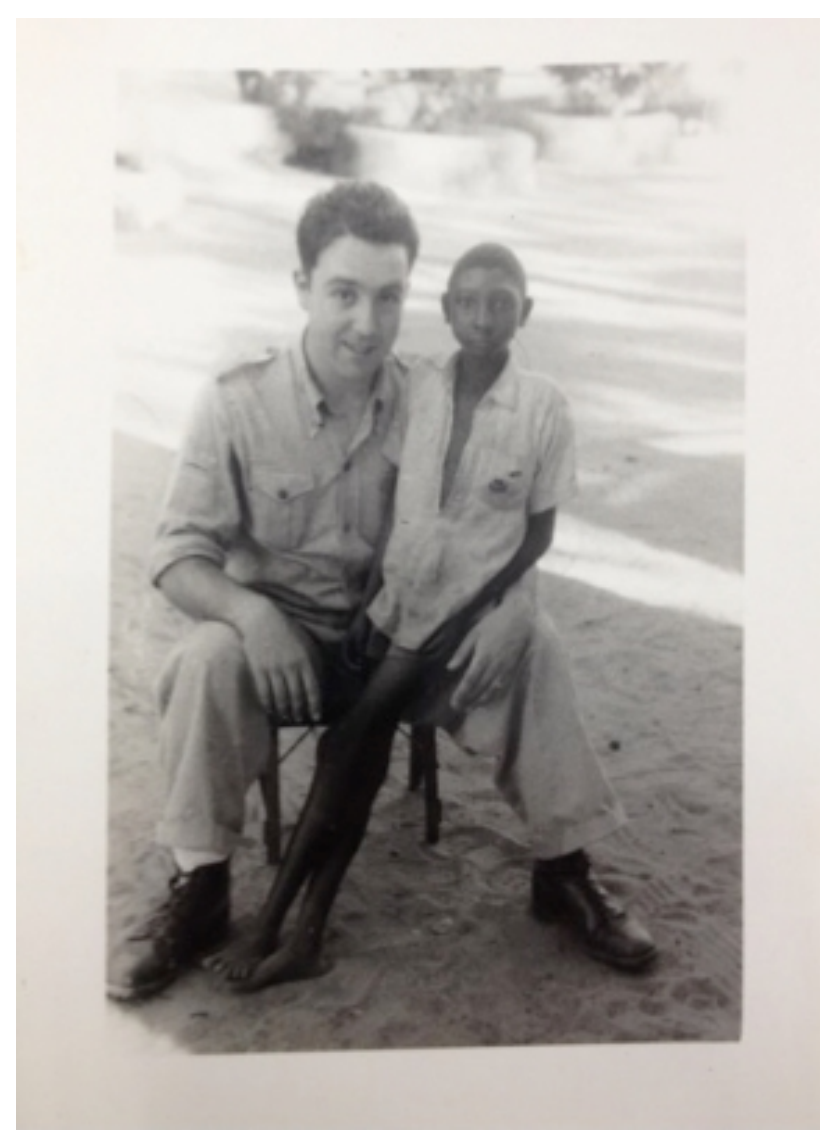

Figura 3. Assistente da MAM com Atomane IICT-Photography Collection, Inv. ULISBOA-IICT-MAM (1948)

A fotografia de Atomane com Norberto tem um detalhe interessante. Refiro-me aos dois alfinetes de fantasia presos ao bolso da camisa de Atomane. Como já foi mencionado anteriormente, Atomane havia recebido alguns alfinetes de fantasia dos membros da equipa da MAM. Um deles lhe foi roubado. Segundo o chefe da MAM, tratava-se do "mais vistoso e certamente o de mais agrado do nosso anãozinho" (Santos Júnior, 1949, p. 2). Não duvido que o alfinete em questão seja o que aparece em destaque no bolso de sua camisa. Se assim for, pode-se inferir que as duas outras fotografias (Figuras 1 e 2) foram feitas depois da fotografia de Norberto e Atomane (Figura 3).

Sabe-se que toda fotografia "isola, preserva e apresenta um momento tirado de um continuum" (Berger, 2017, p. 39). Nesse sentido, a fotografia remete ao que não é visto, ou seja, aquilo que aconteceu antes e depois dela. Para tentar integrar a fotografia de Norberto e Atomane numa continuidade, deve-se ter em conta a provável convocação do pai de Atomane e as medidas e impressões dermopapilares realizadas pelo ajudante da MAM. Depois do instante fotografado, Atomane voltou para casa com seus alfinetes de fantasia. Já o chefe da MAM e o seu filho Norberto retornariam para Portugal, onde apresentariam trabalhos com bases nos dados coligidos em Moçambique. Sabe-se que um mesmo objeto pode ter significados diferentes segundo o ponto de vista individual de diferentes pessoas (Schütz, 1998, p. 25). Diante da câmera fotográfica, Norberto e Atomane têm diferentes expectativas. O primeiro espera ter uma imagem revelada que poderá ter múltiplos usos para si, inclusive como registo visual do "ter estado lá", para usar uma noção de Roland Barthes (2015, p. 67). Já o segundo, o que esperava daquele momento? Acompanhou o seu pai e obedeceu ordens, entre outras, para se deixar fotografar. Provavelmente, não recebeu 
nenhuma fotografia revelada de sua própria imagem. Voltou para casa sem saber que o seu retrato faria parte de uma iconografia teratológica e que suas medidas entrariam para as estatísticas de uma antropologia colonial.

O exame das imagens de corpos anômalos da coleção fotográfica da MAM suscita a seguinte pergunta: afinal, quem eram os monstros na teratologia colonial? Assim como o filme Freaks (1932), de Tod Browning, as fotografias de corpos anômalos em situação colonial nos interpelam e somos levados a perguntar de que lado está a monstruosidade? A espetacularização de corpos enfermos ou anômalos por meio da fotografia ou a exposição na película do sofrimento dos outros não teria algo de indecente?

Quanto ao observador, este observador, mesmo passados muitos anos depois de a fotografia ter sido tirada... bem, podemos ficar de olhos pregados nestes rostos durante muito tempo e não chegarmos ao fim do mistério, e da indecência, do nosso próprio papel como espectador. (Sontag, 2015, p. 61)

Ver as fotografias de Atomane causa um mal-estar, o seu retrato perturba. Ele foi mais do que um caso de "nanismo e infantilismo" para usar os termos de Santos Júnior (1949). Além da espetacularização científica em terras exóticas, o caso do pequenino Atomane desvela uma fascinação que fomentou a produção de imagens de um conjunto heteróclito de corpos anômalos, enfermos e mutilados que, na visão dos chefes das missões antropológicas, fazia da colonização um imperativo categórico para a África. Além das fotografias de microcefalia e de outros casos de malformação congênita, imagens de alargamentos ou perfurações dos lóbulos da orelha ou dos lábios, de limagem dos dentes e de escarificações corporais se encontram no espólio iconográfico da teratologia colonial produzida pelos antropólogos e seus ajudantes nas missões científicas portuguesas?.

Assim como Mendes Corrêa, Santos Júnior era um médico convertido em antropólogo. Não foram poucos os médicos engajados no projeto colonial português. Para Luís de Pina (1934, p. 1), a colonização baseada em princípios científicos seria a panaceia africana. Durante o Estado Novo, o mainstream da medicina tropical e da antropologia colonial fazia crer que, sob a ordem colonial, os "indígenas" deixariam de fazer suas "mutilações étnicas" e poderiam ser curados de muitas enfermidades e anomalias. Na perspectiva colonial, o retrato de Atomane seria como o semblante

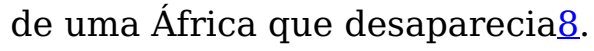

\section{Considerações finais}

Com base em registos de internamentos do século XVIII, Michel Foucault (1977) fez uma "antologia de existências" cujo ponto em comum dessas vidas foi o confronto delas com o poder. Sem esse conflito com a lei, talvez, nenhum rasto dessas existências haveria nos arquivos. Uma outra "antologia de existências" pode ser feita de pessoas que nunca estiveram em conflito com a lei, mas cujos vestígios de suas vidas foram preservados nos arquivos porque a anomalia dos seus corpos foi alvo da curiosidade científica. Dessa última, tem-se o caso de Atomane que, devido a uma anomalia, foi levado pelo seu pai ao encontro da equipa da MAM durante a sua passagem pela localidade de António Enes em setembro de 1948.

O caso de Atomane revela uma faceta escabrosa das campanhas das missões antropológicas à Guiné, Angola, São Tomé e Príncipe, Moçambique e Timor, realizadas entre 1936 e 1959. Não raro, o espetáculo da anomalia exagerava a sua representação, pois esses casos eram residuais no conjunto de dados empíricos para formulações de políticas "indígenas", entre outros. Sem levar em conta possíveis constrangimentos, o chefe da MAM fez do "homenzinho" de António Enes um caso espetacular. Atomane foi objeto de um estudo científico que Santos Júnior apresentou em comunicação intitulada Um caso de nanismo completo ou total num preto de António Enes, 
Moçambique, durante o "VI Congresso de Anatomia Luso-Hispano-Americano" e a "XIX Reunião da Sociedade Anatómica Portuguesa", realizada em Lisboa, entre 15 e 18 de maio de 1949. O interesse de Santos Júnior pelas anomalias em Moçambique tem sua interface com uma teratologia colonial. Mas o que revela a espetacularização científica dos corpos anômalos? O espetáculo do mórbido não seria mais um desdobramento da obstinada busca pela normalidade?

Assim como a fotografia extrai um momento de uma continuidade (Berger, 2017, p. 39), o relatório de Santos Júnior (1949) sobre o "microcéfalo de António Enes" abstrai a interação social do antropólogo com o "indígena" da situação colonial em que ela transcorreu $\underline{9}$. A experiência intersubjetiva do antropólogo com a alteridade é vazada pela ação racional do primeiro assente numa pretensa normalidade - e superioridade - explícita na tentativa de uma comunicação intercultural em situação colonial. Acontece que o outro também interagiu racionalmente a partir da sua realidade e de suas convenções, malgrado o fato dos membros da MAM ignorarem as províncias de significado ou as múltiplas realidades em que eles e os outros se encontravam. Considerar as províncias de significado de indivíduos em situação colonial parece imprescindível para estudar o campo de produção de imagens e como ocorreram certas experiências intersubjetivas. Desse modo, pode-se melhor avaliar os limites da comunicação intercultural entre diferentes atores envolvidos (in)voluntariamente nas campanhas da MAM.

\section{Agradecimentos}

Este trabalho foi realizado no âmbito das atividades de investigação do projeto "Photo Impulse" (PTDC/COM-OUT/29608/2017) do ICNOVA e beneficiou do uso da

infraestrutura PRISC (Portuguese Research Infrastructure of Scientific Collections). Contou ainda com o apoio da Coordenação de Aperfeiçoamento de Pessoal de Nível Superior - Brasil (Capes, proc. 88881.171249/2018-01), do Conselho Nacional de Desenvolvimento Científico e Tecnológico (CNPq, proc. 303543/2020-5). O autor agradece ainda Catarina Mateus, da Conservação e Curadoria de Coleções Fotográficas, Programa Promoção do Saber Tropical - Memórias e Património nos Arquivos Fotográficos do Instituto de Investigação Científica Tropical/Universidade de Lisboa.

\section{Nota biográfica}

Sílvio Marcus de Souza Correa é professor associado no Departamento de História da Universidade Federal de Santa Catarina (Brasil) e doutor pela Westfälische-Wilhelms-Universität Münster (Alemanha). Foi investigador visitante no Instituto de Investigação Científica Tropical de Lisboa, Instituto de Estudos Avançados de Paris, Centre d'Etudes en Sciences Sociales sur les Mondes Africains, Américains et Asiatiques da Universidade Paris 7 e Centro Interuniversitário de História da Ciência e da Tecnologia da Universidade Nova de Lisboa. É membro da equipa de investigadores do projeto "Photo Impulse" (PTDC/COM-OUT/29608/2017) do Instituto de Comunicação da NOVA. Seus trabalhos mais recentes tratam da história visual do colonialismo e da representação iconográfica da África e dos africanos.

ORCID: https://orcid.org/0000-0002-0364-6590

Email: silvio.correa@ufsc.br

Morada: Universidade Federal de Santa Catarina - UFSC - CFH - Bairro Trindade, Florianópolis SC, 88040-970, Brasil

\section{Notas}

1. A atual cidade de Angoche, na província de Nampula, em Moçambique, chamava-se António Enes 
durante o período colonial.

2. Como bem demonstrou Susan Sontag (1975) em sua resenha ao livro The last of the Nuba, da fotógrafa alemã Leni Riefenstahl, o fascinating fascism pode revelar-se em fotografias da alteridade africana.

3. Sobre degenerescência e miscigenação na Antropologia Portuguesa do último quartel do século XIX, ver Joaquim António Fernandes dos Santos (2002, pp. 116-120).

4. Sobre a objetividade atribuída à fotografia, ver, por exemplo, o prefácio de Luciano Cordeiro ao álbum fotográfico e descritivo, intitulado África Ocidental, de José Augusto da Cunha Moraes (1885).

5. Sobra a reconceptualização do campo e as potencialidades da imagem fotográfica na Antropologia Visual, ver o artigo de Sofia Caldeira (2017).

6. Sobre imagem e racismo, o dossiê organizado por Ana Cristina Pereira, Michelle Salles e Rosa Cabecinhas (2020) contém algumas contribuições que têm interface com a (in)visibilidade do sujeito fotografado em situação colonial.

7. Sobre a espetacularização dos corpos enfermos ou anômalos, vale lembrar que imagens de corpos deformados pela lepra ou com sintomas de doenças tropicais como a tripanossomíase humana africana eram exibidas em revistas ilustradas da imprensa periódica metropolitana e em diversos meios de propaganda colonial ou missionária. Nas exposições coloniais, standes reproduziam em grande formato fotografias de serviços de saúde e de higiene, de campanhas sanitárias e também de numerosos casos de doenças tropicais.

8. Ao contrário da importância que a fotografia teve para uma etnografia de urgência que acreditava que as chamadas "sociedades primitivas" estavam destinadas a um inevitável desaparecimento (Caldeira, 2017, p. 170), a fotografia dos corpos anômalos não teve o mesmo apelo.

9. Em meados do século XX, Michel Leiris (1950) tratou da deontologia do etnógrafo perante o colonialismo e fez uma reflexão crítica sobre a ambiguidade dos cientistas sociais em contexto colonial.

\section{Referências}

Barthes, R. (2015). A câmara clara. Nota sobre a fotografia. Nova Fronteira.

Berger, J. (2017). Para entender uma fotografia. Companhia das Letras.

Bombarda, M. (1894). Contribuições para o estudo dos microcephalos. Typographia da Academia Real das Sciencias.

Caldeira, S. (2017). As potencialidades do estudo da imagem fotográfica na antropologia visual. Vista, 1, 165-180. https://doi.org/10.21814/vista.2983

Cascais, A. F. (2016). A inquietante estranheza da microcefalia, modelo da fotografia psiquiátrica em Portugal. Revista de Comunicação e Linguagens, 45, 97-120.

http://www.fcsh.unl.pt/rcl/index.php/rcl/article/view/88

Coelho, A. (1893). Os povos extraeuropeus e em especial os negros da África ante acivilização europeia. Typographia da Companhia Nacional Editora. 
Decreto-Lei 26.842, de 28 de julho de 1936, Diário do Governo, 1aㅡ série, n.o 175 (1936).

Decreto-Lei 34.478, de 3 de abril de 1945, Diário do Governo, 1aㅡ série, n.o 70 (1945).

Foucault, M. (1977). Vigiar e punir, história da violência nas prisões. Vozes.

Freire, B. (1886). Os degenerados. Imprensa da Universidade de Coimbra.

Leiris, M. (1950). O etnógrafo perante o colonialismo. In M. Sanchez (Ed.), As malhasque os impérios tecem. Textos anticoloniais, contextos pós-coloniais (pp.199-217). Edições 70.

Macedo, F. F. (1877). Mapa sintético físico-intelecto-moral dos habitantes das nações percorridas pelo Doutor Francisco Ferraz de Macedo de 1874 a 1877.

Macedo, F. F. (1899). Degeneração e degenerados na sociedade. Tipografia do Comércio.

Macedo, F. F. (1900). Bosquejos de anthropologia criminal. Imprensa Nacional.

Malinkowski, B. (1922). Argonauts of the Western Pacific. G. Routledge \& Sons.

Matos, J. (1911). Elementos de psiquiatria. Lello \& Irmão.

Matos, P. F. (2014). A fotografia na obra de Mendes Correia (1888-1960): Modos de representar, diferenciar e classificar da 'antropologia colonial'. In F. L. Vicente (Ed.), O império da visão: Fotografia no contexto colonial português (1860-1960)(pp. 45-66). Edições 70.

Moraes, J. A. C. (1885). África ocidental. David Corazzi Editor.

Morel, B.-A. (1857). Traité des dégénérescences physiques et morales de l'espècehumaine. J.-B. Baillière.

Neves, J. A. (1898). Um caso de meia microcefalia. Medicina Contemporânea, 43.

Pereira, A. C., Sales, M., \& Cabecinhas, R. (Eds.). (2020). (In)Visibilidades: imagem e racismo [Edição temática]. Vista, 6. https://revistavista.pt/index.php/vista/issue/view/149

Pereira, R. (2005). Raça, sangue e robustez: Os paradigmas da antropologia física colonial portuguesa. Cadernos de Estudos Africanos, 7/8, 209-241.

Pina, L. (1934). Colonização e ciência. Ultramar, 6, 1.

Portaria n. 12.215, de 26 de dezembro de 1947, Diário do Governo, 1o Série, n.o 229.

Rodrigues, M. C. (1990). A investigação de ontem e a sua contribuição para um melhor conhecimento do futuro. In Homenagem a J. R. dos Santos Júnior (Vol. 1, pp. 11-30). IICT.

Roma, E. (1913). A microcefalia. [Dissertação, Universidade de Lisboa].

Roque, A. C., \& Ferrão, L. (2012). Documentação da missão antropológica de Moçambique relatório da 5a campanha (1948). Povos e Culturas, (16), 221-328.

https://doi.org/10.34632/povoseculturas.2012.8909

Santos Júnior, J. R. (1939). Anomalias dos membros em negros da Zambézia Portuguesa. Moçambique - documentário trimestral, 17, 37-72. 
Santos Júnior, J. R. (1944). Contribuição para o estudo da antropologia de Moçambique: Nhúngüés e Antumbas [Tese de doutoramento, Universidade do Porto].

Santos Júnior, J. R. (1945). Contribuição para o estudo da antropologia de Moçambique: Algumas tribos do distrito de Tete. Memórias da Junta das Missões Geográficas e deInvestigações Coloniais, 2 .

Santos Júnior, J. R. (1948). Relatório 5a campanha. Universidade de Lisboa/IICT-MAM.

Santos Júnior, J. R. (1949, 15-18 maio). Um caso de nanismo completo ou total num preto de António Enes - Moçambique (manuscrito) [Apresentação de Comunicação]. VI Congresso Anatómico Luso-Hispano-Americano e XIV Reunião da Sociedade Anatómica Portuguesa, Universidade de Lisboa/IICT- MAM, Lisboa, Portugal.

Santos, J. A. F. (2002). Do império da raça à "raça do império" (etnicidade ecolonialismo, 1870-1914) [Dissertação de mestrado, Universidade de Coimbra].

Schütz, A. (1998). Éléments de sociologie phénoménologique. L’Harmattan.

Sontag, S. (1975, 6 de fevereiro). Fascinating fascism. New York Review of Books. https://www.nybooks.com/articles/1975/02/06/fascinating-fascism/

Sontag, S. (2015). Olhando o sofrimento dos outros. Quetzal.

Este trabalho está licenciado com uma Licença CreativeCommons- Atribuição 4.0 Internacional. 